\title{
The Lipid Status in Patients with Ulcerative Colitis: Sphingolipids are Disease-Dependent Regulated
}

\author{
Sarah Bazarganipour ${ }^{\dagger, 1}$, Johannes Hausmann ${ }^{\dagger, 2}{ }^{-0}$, Stephanie Oertel ${ }^{1}$, Khadija El-Hindi ${ }^{1}$, \\ Sebastian Brachtendorf ${ }^{1}$, Irina Blumenstein ${ }^{2}$, Alica Kubesch ${ }^{2}{ }^{-}$, Kathrin Sprinzl ${ }^{2}$, \\ Kerstin Birod 1, Lisa Hahnefeld ${ }^{1}$, Sandra Trautmann ${ }^{1}$, Dominique Thomas ${ }^{1}(1)$, Eva Herrmann ${ }^{3}$, \\ Gerd Geisslinger ${ }^{1,4}$, Susanne Schiffmann ${ }^{4}$ and Sabine Grösch ${ }^{1, *}$ \\ 1 Institute of Clinical Pharmacology, Goethe University Hospital, Theodor-Stern-Kai 7, \\ 60590 Frankfurt/Main, Germany \\ 2 First Department of Internal Medicine, Division of Gastroenterology, Goethe University Hospital, \\ Theodor-Stern-Kai 7, 60590 Frankfurt/Main, Germany \\ 3 Institute for Biostatistics and Mathematical Modelling, Goethe University, Theodor-Stern-Kai 7, \\ 60590 Frankfurt/Main, Germany \\ 4 Fraunhofer Institute for Molecular Biology and Applied Ecology IME, Branch for Translational Medicine and \\ Pharmacology TMP, Theodor-Stern-Kai 7, 60596 Frankfurt/Main, Germany \\ * Correspondence: groesch@em.uni-frankfurt.de; Tel: +49-69-6301-7820; Fax: +49-69-6301-7636 \\ + Contributed equally.
}

Received: 22 May 2019; Accepted: 2 July 2019; Published: 4 July 2019

check for updates

\begin{abstract}
The factors that contribute to the development of ulcerative colitis (UC), are still not fully identified. Disruption of the colon barrier is one of the first events leading to invasion of bacteria and activation of the immune system. The colon barrier is strongly influenced by sphingolipids. Sphingolipids impact cell-cell contacts and function as second messengers. We collected blood and colon tissue samples from UC patients and healthy controls and investigated the sphingolipids and other lipids by LC-MS/MS or LC-QTOFMS. The expression of enzymes of the sphingolipid pathway were determined by RT-PCR and immunohistochemistry. In inflamed colon tissue, the de novo-synthesis of sphingolipids is reduced, whereas lactosylceramides are increased. Reduction of dihydroceramides was due to posttranslational inhibition rather than altered serine palmitoyl transferase or ceramide synthase expression in inflamed colon tissue. Furthermore, in human plasma from UC-patients, several sphinglipids change significantly in comparison to healthy controls. Beside sphingolipids free fatty acids, lysophosphatidylcholines and triglycerides changed significantly in the blood of colitis patients dependent on the disease severity. Our data indicate that detraction of the sphingolipid de novo synthesis in colon tissue might be an important trigger for UC. Several lipids changed significantly in the blood, which might be used as biomarkers for disease control; however, diet-related variabilities need to be considered.
\end{abstract}

Keywords: ceramide; sphingolipid; ulcerative colitis; LC-MS/MS; S1P; EPA; DHA; patient

\section{Introduction}

Ulcerative colitis (UC) is a chronic disease characterized by diffuse inflammation of the rectal and colonic mucosa. The occurrence of UC has increased worldwide over the past few years [1-3]. The highest incidence of ulcerative colitis has been reported in Northern Europe $(24.3$ per 100,000) [3]. Patients most commonly complain about increased frequency and often bloody stools, abdominal pain, weight loss and general reduced quality of life. The clinical course is characterized by periods of remission and exacerbation, which may occur either spontaneously or in response to medical 
treatment. The primary aim of medical management is to induce and maintain remission with the long-term goals of preventing disability, colectomy, and colorectal cancer. Targets for remission include resolution of clinical symptoms, defined as cessation of rectal bleeding and improvement in bowel habits, and endoscopic healing, which is frequently defined as an endoscopic Mayo score of zero or one $[4,5]$. The selection of medications is guided by disease severity and extent. Mesalamine is a trusted standby for patients with mild-to-moderate UC. In cases of more severe inflammation, the use of systemic steroids, immunosuppressants (azathioprine and 6-mercaptopurine) and biologicals (antibodies against tumor necrosis factor alpha (TNF $\alpha$ ) or integrin $\left.\alpha_{4} \beta_{7}\right)$ is often warranted for disease control and to maintain remission. Several guidelines $[6,7]$ are available to assist the physician in making his decision. However, use of these drugs is not without immediate and delayed risks such as infections, allergic reactions, development of psoriasis and an increased risk of malignancies. Thus, research has been focused on developing targeted immunomodulatory drugs aiming to potentially address colonic inflammation whilst avoiding a general alteration of immune response. One promising approach is the inhibition of the sphingosine-1-phosphate (S1P) signaling pathway by interfering with S1P receptors (S1PR). S1P signaling regulates inflammation via its impact on the trafficking, differentiation, and effector functions of bone-marrow-derived immune cells [8]. In the treatment of multiple sclerosis, S1PR agonists (like fingolimod) have already been applied and show enticing results [9]. Fingolimod operates through internalizing and consecutively degrading the S1PR1 in lymphocytes, thus enabling immune cells to leave secondary lymph nodes in the blood stream [10-12]. Phase III clinical trials using a S1PR1/5 agonist (ozanimod) for UC are currently ongoing and phase I and II results appeared promising [13]. S1P belongs to the group of sphingolipids which play a distinct role as a second messenger in signaling pathways and are essential for physiological properties of cell membranes [14,15]. Beside S1P, several other sphingolipids have been shown to be deregulated in various diseases, especially under inflammatory conditions [12,16-19]. Ceramides and their complex derivatives are main components of membranes and their deregulation impacts cell signaling and the fate of the cell [20]. Sphingolipids are synthesized either by the de novo synthesis or the salvage pathway. The serine palmitoyl transferase (SPT) is the first rate-limiting enzyme in the de novo synthesis, catalyzing the condensation of serine and palmitoyl-CoA to sphinganine. Six homologous ceramide synthases (CerS) attach various acyl-CoA side chains to sphinganine or sphingosine, generating either dihydroceramide (dhCer) or ceramide (Cer). They have chain length preferences using C14to C26-acylCoAs. CerS1 mainly synthesizes C18-Cer, CerS4 synthesizes C18-/C20-Cer, CerS5 and CerS6 mainly synthesize C14- and C16-Cer, CerS2 synthesizes the long-chain C22/C24-Cer, and CerS3 synthesizes long ceramides with a chain length of up to C34 [21,22]. CerS are expressed tissue-specific and are regulated at transcriptional as well as posttranscriptional levels [23]. Ceramides are converted in the Golgi apparatus either to hexyl-ceramides or sphingomyelins, which are main components of cellular membranes. In the salvage pathway, complex sphingolipids are degraded back to ceramides and sphingosine, which could be phosphorylated to S1P and ceramide-1-phosphate (C1P). Recently published studies from human patients suffering from inflammatory bowel disease (UC or Crohn's disease (CD)) give the first hint that the sphingolipid rheostat is deregulated in UC, however, the data are either generated from stool probes [24] or in untreated patients $[25,26]$. Furthermore, findings in various mice deficient of an enzyme in the sphingolipid pathway, indicate that sphingolipids play an important role in the development of ulcerative colitis [27-35]. These data indicate that the sphingolipid pathway, and especially the balance between different sphingolipids, may impact the development or progression of colitis. Against the background of this knowledge, we investigated the sphingolipid status and other lipids in human plasma, white blood cells and colon biopsies from UC patients. We analyzed whether differences in the sphingolipid status could be observed depending on disease severity and medical treatment in UC patients and whether lipids in the blood might be determined as biomarkers for disease control. 


\section{Experimental Section}

\subsection{Cohort}

We included 98 patients who applied to the IBD outpatient clinic of the University Hospital Frankfurt with diagnosed ulcerative colitis between 2014 and 2018 in this prospective study. Inclusion criteria were age above 18 years, diagnosed ulcerative colitis, as well as written informed consent to participate in the study. Exclusion criteria were an age below 18 years, no definitive diagnosis of UC and underlying liver diseases. The patients were followed up at the treating physician's discretion, usually every 6-12 weeks. In the course of the observation time, repeated blood samples were obtained from most patients. As some patients changed their disease stage during this time, we could compare intra- and inter-individual changes in our dataset (see also Figure S1). Blood samples were obtained during clinically indicated routine laboratory diagnostics and kept on ice for 1-4 hours prior to further analysis. Clinical parameters such as partial Mayo score (Table S1), duration and localization of disease, and UC medication were assessed during patient visits (see Tables 1 and 2). Furthermore, colon samples were collected from 59 European patients undergoing diagnostic colonoscopy at the department of Gastroenterology of the University Hospital Frankfurt. Biopsies were obtained from inflamed and non-inflamed sections of the colon. Non-inflamed control samples were taken from the same patients $2-5 \mathrm{~cm}$ above the location where samples of inflamed tissue were biopsied. All tissue samples were freshly frozen and stored at $-80^{\circ} \mathrm{C}$ immediately after resection. Furthermore, 148 control blood samples were taken from 25 healthy volunteers-repeated blood draw within one year, according to the patient samples-with a mean age of 40.9 years and kept on ice for 1-4 hours prior to further analysis. The study was conducted according to the declaration of Helsinki, and approval was obtained from the local ethics committee. Reference number: 296/14 and 77/15. A written informed consent was obtained from patients and volunteers prior to enrollment in the study.

Table 1. qRT-PCR primer.

\begin{tabular}{|c|c|c|}
\hline Gene & Primer Sequence & Manufacturer \\
\hline Sptlc2 & $\begin{array}{l}\text { Fw 5'-TATGGAGCTGGAGTGTGCAG-3' } \\
\text { Rev 5'-GAATTCGTTGCAAATCCCAT-3' }\end{array}$ & biomers, Ulm Germany \\
\hline Sptlc3 & $\begin{array}{l}\text { Fw 5'-GTATGATGAGTCTATGAGGAC-3' } \\
\text { Rev 5'-CATTCAGGAACTTAGCCACA-3' }\end{array}$ & biomers, Ulm Germany \\
\hline CerS1 & $\begin{array}{l}\text { Fw 5'-CCTCCAGCCCAGAGAT-3' } \\
\text { Rev 5'-AGAAGGGGTAGTCGGTG-3' }\end{array}$ & biomers, Ulm, Germany \\
\hline CerS2 & $\begin{array}{c}\text { Fw 5'-CCAGGTAGAGCGTTGGTT-3' } \\
\text { Rev 5'-CCAGGGTTTATCCACAATGAC-3' }\end{array}$ & biomers, Ulm, Germany \\
\hline CerS3 & $\begin{array}{c}\text { Fw 5'-CCTGGCTGCTATTAGTCTGAT-3' } \\
\text { Rev 5'-TCACGAGGGTCCCACT-3' }\end{array}$ & biomers, Ulm, Germany \\
\hline CerS4 (WBC) & $\begin{array}{l}\text { Fw 5'-CTG GTG GTA CCT CTT GGA GC-3' } \\
\text { Rev 5'-CGT CGC ACA CTT CTA ATA CC-3' }\end{array}$ & biomers, Ulm, Germany \\
\hline CerS4 (tissue) & $\begin{array}{l}\text { Fw 5'-CTG GTG GTA CCT CTT GGA GC-3' } \\
\text { Rev 5'-AGC AAC ATC AGA AGC CCG TT-3' }\end{array}$ & biomers, Ulm, Germany \\
\hline CerS5 & $\begin{array}{c}\text { Fw 5'-CAAGTATCAGCGGCTCTGT-3' } \\
\text { Rev 5'-ATTATCTCCCAACTCTCAAAGA-3' }\end{array}$ & biomers, Ulm, Germany \\
\hline CerS6 & $\begin{array}{c}\text { Fw 5' } \text { 5'AAGCAACTGGACTGGGATGTT-3' }^{\prime} \\
\text { Rev 5'-AATCTGACTCCGTAGGTAAATACA-3' }\end{array}$ & biomers, Ulm, Germany \\
\hline GAPDH & $\begin{array}{c}\text { Fw 5'-CCA GGA GCG AGA TCC CTC-3' } \\
\text { Rev 5'-GGG CAG AGA TGA TGA CCC TT-3' }\end{array}$ & biomers, Ulm, Germany \\
\hline
\end{tabular}


Table 2. Patient data.

\begin{tabular}{ccc}
\hline $\begin{array}{c}\text { Gender } \\
\text { all patients }\end{array}$ & number & $\mathbf{( \% )}$ \\
male & $51 / 98$ & $(55)$ \\
female & $47 / 98$ & $(45)$ \\
colon-biopsis & & \\
male & $37 / 59$ & $(63)$ \\
female & $22 / 59$ & $(37)$ \\
blood samples & & \\
male & $105 / 183$ & $(57)$ \\
female & $78 / 183$ & $(43)$ \\
Median age & $43.8(19-76)$ years & \\
Median disease duration & $11(1-62)$ years & \\
Disease status using partial mayo score (\%) & & \\
remission & $109 / 183$ & $(60)$ \\
mild & $45 / 183$ & $(24)$ \\
moderate/severe & $29 / 183$ & $(16)$ \\
Severity of disease (\%) & & \\
pancolitis & $86 / 183$ & $(47)$ \\
extensive colitis & $9 / 183$ & $(5)$ \\
left side colitis & $43 / 183$ & $(23)$ \\
sigmoiditis & $25 / 183$ & $(14)$ \\
proktitis & $14 / 183$ & $(8)$ \\
not mentioned & $6 / 183$ & $(3)$ \\
\hline
\end{tabular}

\subsection{Isolation of White Blood Cells (WBCs) from Blood Samples}

About $9 \mathrm{~mL}$ whole-blood samples from UC patients or controls were collected in EDTA blood collection tubes and kept on ice for 1-4 hours until isolation of white blood cells (WBCs). For WBC-isolation, blood was centrifuged for $10 \mathrm{~min}$ at $2000 \times \mathrm{g}$ at $4{ }^{\circ} \mathrm{C}, 1 \mathrm{~mL}$ plasma was taken and stored in aliquots at $-80{ }^{\circ} \mathrm{C}$ for further analysis by LC-MS/MS. A quantity of $1 \mathrm{~mL}$ of PBS phosphate-buffered saline was added to the blood sample collection tube containing WBCs, erythrocytes, and plasma inverted several times and incubated with $45 \mathrm{~mL}$ erythrocyte-lysis buffer $\left(135 \mathrm{mM} \mathrm{NH}_{4} \mathrm{Cl}\right.$; $10 \mathrm{mM} \mathrm{NaHCO} 3 ; 0,1 \mathrm{mM} \mathrm{Na}-\mathrm{EDTA}$ ) for $10 \mathrm{~min}$ at RT and centrifuged at $600 \times \mathrm{g}$ for $10 \mathrm{~min}$. The WBC cell pellet was incubated again with $1 \mathrm{~mL}$ erythrocyte-lysis buffer for an additional $5 \mathrm{~min}$, centrifuged at $300 \times \mathrm{g}$ for $5 \mathrm{~min}$ and washed before being stored at $-80^{\circ} \mathrm{C}$ or directly used for RNA extraction.

\subsection{Real-Time $q P C R$}

The mRNA from colon biopsies was extracted with the RNeasy Lipid Tissue Mini Kit (Quiagen, Hilden, Germany) according to the manufacturer's instructions. About 2-5 mg of colon tissue was homogenized in $1 \mathrm{~mL}$ QIAzol lysis reagent, incubated for $5 \mathrm{~min}$ at RT before $200 \mu \mathrm{L}$ chloroform was added. After centrifugation ( $15 \mathrm{~min}, 12,000 \mathrm{~g}, 4^{\circ} \mathrm{C}$ ), the upper phase (containing RNA) was applied to an RNeasy spin column, here the total RNA/DNA binds to the membrane. DNA was removed using DNase I and RNA was eluted in $30 \mu \mathrm{L}$ of RNase-free water. RNA from white blood cells (WBCs) was isolated using the RNeasy Mini kit (Quiagen, Hilden, Germany) according to the manufacturer's instructions. RNA content from tissue or WBC was determined using the NanoQuant Plate ${ }^{\mathrm{TM}}$ and the Tecan plate reader (Tecan, Männedorf, Switzerland). The cDNA synthesis was performed using the Verso $^{\mathrm{TM}}$ cDNA-Synthesis kit (Thermo Scientific, Schwerte, Germany), including an enhancer enzyme. The expression levels of CerS1, CerS2, CerS3, CerS4, CerS5, CerS6, Sptlc2, Sptlc3 and GAPDH were determined using the Syber Select Master Mix (Thermo Fisher Scientific, Darmstadt, Germany) with an ABI Prism 7500 Sequence Detection System (Applied Biosystems, Thermo Fisher, Damstadt, Germany). Relative mRNA expression was determined using the comparative $\Delta \Delta C T$ (cycle threshold) method, normalizing relative values to the expression level of human GAPDH. The sequences for the primer 
sets are shown in Table 1. Linearity of the assays was determined by serial dilutions of the templates for each primer set separately.

\subsection{Liquid Chromatography Tandem Mass Spectrometry (LC-MS/MS) Analysis of Sphingolipids}

Quantification of sphingolipids from tissue and plasma samples was performed by high-performance liquid chromatography tandem mass spectrometry. For quantification of sphingolipids, the tissue samples were first mixed with water and homogenized to a suspension of $0.05 \mathrm{mg} / \mu \mathrm{L}$ tissue using a swing mill (Retsch, Haan, Germany) with four zirconium oxide grinding balls for each sample ( $25 \mathrm{~Hz}$ for 2.5 minutes).

A quantity of $40 \mu \mathrm{L}$ of the tissue suspension (in total $2 \mathrm{mg}$ tissue) was mixed with $160 \mu \mathrm{L}$ water, or $10 \mu \mathrm{L}$ plasma was mixed with $190 \mu \mathrm{L}$ water, together with $200 \mu \mathrm{L}$ extraction buffer (citric acid $30 \mathrm{mM}$, disodium hydrogen phosphate $40 \mathrm{mM}$ ) and $20 \mu \mathrm{L}$ of the internal standard solution containing sphingosine-d7, sphinganine-d7, sphingosine-1-phosphate-d7, C17-Cer, C16-Cer-d7, C18-Cer-d3, C24-Cer-d4, C17-LacCer, C18-dhCer-d3, C16-LacCer-d3 and C18-GlcCer-d5. The mixture was extracted twice with $600 \mu \mathrm{L}$ methanol/chloroform/hydrochloric acid (15:83:2, v/v/v). The collected lower organic phases were evaporated at $45^{\circ} \mathrm{C}$ under a gentle stream of nitrogen and reconstituted in $100 \mu \mathrm{L}$ of tetrahydrofuran/water $(9: 1, \mathrm{v} / \mathrm{v})$ with $0.2 \%$ formic acid and $10 \mathrm{mM}$ ammonium formate. Afterwards, amounts of sphingosine, sphingosine-1-phosphate, sphinganine, sphinganine-1-phosphate, C16:0-Cer, C18:0-Cer, C18:1-Cer, C20:0-Cer, C24:0-Cer, C24:1-Cer, C16:0-GlcCer, C16:0-dhCer, C18:0-dhCer, C24:1-dhCer were analyzed by LC-MS/MS. A Luna C8 column $(150 \mathrm{~mm} \times 2 \mathrm{~mm}$ ID, $3 \mu \mathrm{M}$ particle size, $100 \AA$ A pore size; Phenomenex, Aschaffenburg, Germany) was used for chromatographic separation. The HPLC mobile phases consisted of water with $0.2 \%$ formic acid and $2 \mathrm{mM}$ ammonium formate (A) and acetonitrile/isopropanol/acetone (50:30:20, v/v/v) with $0.2 \%$ formic acid (B). For separation, a gradient program was used at a flow rate of $0.3 \mathrm{~mL} / \mathrm{min}$. The initial buffer composition $55 \%$ (A) $/ 45 \%$ (B) was held for $0.7 \mathrm{~min}$ and then, within $4.0 \mathrm{~min}$, linearly changed to $0 \%(\mathrm{~A}) / 100 \%$ (B) and held for $13.3 \mathrm{~min}$. Subsequently, the composition was linearly changed within $1.0 \mathrm{~min}$ to $75 \%$ (A)/25\% (B) and then held for another $2.0 \mathrm{~min}$. The running time was $21 \mathrm{~min}$ and the injection volume was $15 \mu \mathrm{L}$. After every sample, the sample solvent was injected for washing the column with a $12 \mathrm{~min}$ run. The MS/MS analyses were performed using a triple quadrupole mass spectrometer API4000 (Sciex, Darmstadt, Germany) equipped with an Electrospray Ionization (ESI) ion source. The analysis was performed in Multiple Reaction Monitoring (MRM) mode with a dwell time of $25 \mathrm{~ms}$.

Data acquisition was carried out using Analyst Software V 1.6 and quantification was performed with MultiQuant Software V 3.0 (both Sciex, Darmstadt, Germany), employing the internal standard method (isotope dilution mass spectrometry). Variations in the accuracy of the calibration standards were less than $15 \%$ over the whole range of calibration, except for the lower limit of quantification, where a variation in accuracy of $20 \%$ was accepted.

\subsection{Liquid Chromatography Quadrupole-time-of-flight Mass Spectrometry (LC-QTOFMS) Analysis of Lipids in Plasma}

Plasma samples $(20 \mu \mathrm{L})$ were extracted using methyl-tert-butyl-ether [1]. After re-extraction, the combined organic phases were separated into two aliquots. After drying under a nitrogen stream at $45^{\circ} \mathrm{C}$ and stored at $-40{ }^{\circ} \mathrm{C}$ pending analysis. The aliquots for negative ion mode were reconstituted in $60 \mu \mathrm{L}$ methanol and those for positive ion mode in $60 \mu \mathrm{L}$ of methanol/chloroform (2:1, v/v). LC-MS analysis was performed on a Nexera X2 system (Shimadzu Corporation, Kyoto, Japan) coupled with a TripleTOF 6600 with a DuoSpray ion source (Sciex, Darmstadt, Germany). The chromatographic separation was done on a Zorbax RRHD Eclipse Plus C8 $1.8 \mu \mathrm{M} 50 \times 2.1 \mathrm{~mm}$ ID column (Agilent, Waldbronn, Germany) with a SecurityGuard Ultra C8 pre-column (Phenomenex, Aschaffenburg, Germany), using a binary gradient with $40{ }^{\circ} \mathrm{C}$ column temperature and a flow rate of $0.3 \mathrm{~mL} / \mathrm{min}$. The mobile phase A consisted of $10 \mathrm{mM}$ ammonium formate and $0.1 \%$ formic acid in water and mobile phase B consisted of $0.1 \%$ formic acid in acetonitrile: isopropanol $(2: 3, \mathrm{v} / \mathrm{v})$. The initial buffer 
composition with $20 \%$ B was held for $0.3 \mathrm{~min}$, increased to $80 \%$ after $3.2 \mathrm{~min}$, further increased to $100 \%$ after $7.0 \mathrm{~min}$, held $100 \% \mathrm{~B}$ for $2.5 \mathrm{~min}$ and reverted to $20 \% \mathrm{~B}$ after $1.5 \mathrm{~min}$, following a $2.5 \mathrm{~min}$ equilibration. For the negative measurement, $1 \mathrm{mM}$ ammonium formate and $0.1 \%$ formic acid in water was used as mobile phase A. The run time was 17 minutes per polarity and the injection volumes were $2 \mu \mathrm{L}$ for positive and $5 \mu \mathrm{L}$ for negative ionization mode, respectively.

The MS analysis consisted of a TOF MS Scan from 100-1000 m/z with $250 \mathrm{~ms}$ of accumulation time and six data-dependent acquisitions per cycle with a mass range of 50-1000 m/z and $50 \mathrm{~ms}$ of accumulation time. Data acquisition was performed using Analyst TF 1.7 software and peak integration for semi-targeted comparison was done using MultiQuant V 3.02 (both Sciex, Darmstadt, Germany). The identification of the lipid species was based on the exact mass (+/- $5 \mathrm{ppm})$, the isotope ratio and the comparison of the MS/MS spectra with the reference spectra according to LIPID MAPS (http://www.lipidmaps.org) or METLIN (http://metlin.scripps.edu). Peak areas were normalized to the first quality control sample using median peak ratios by MarkerView 1.2 software (Sciex, Darmstadt, Germany) with a mass accuracy window of $10 \mathrm{ppm}$ and 0.15 minutes retention time tolerance window for peak alignment. By normalizing with the median peak ratio, samples were corrected with a scale factor calculated from the median of the peak area ratio for each sample and a set reference sample for all peaks with a peak area greater than $1 \%$ of the largest peak of the reference sample. This method is more robust against asymmetrical intensity increase than the total intensity or total area sum normalization and hence can also be utilized for samples with changes in the content of more abundant lipids.

All samples were randomized prior to extraction. Pooled quality control samples were injected four times at the start and at the end of the run and after every ten samples to verify system stability.

\subsection{Immunohistochemistry}

CerS protein expression was detected in colon tissue biopsies.

For immunohistochemistry, $10 \mu \mathrm{M}$ tissue sections were placed in $100 \%$ ice-cold methanol for $10 \mathrm{~min}$ and subsequently, in 100\% acetone for one minute. Slices were washed and permeabilized in PBS containing $0.025 \%$ Triton X-100 for $2 \times 5$ min, then blocked in PBS containing $3 \%$ bovine serum albumin and $10 \%$ normal goat serum for $90 \mathrm{~min}$ at room temperature. The sections were incubated with anti-CerS3 (Sigma) primary antibody at $4{ }^{\circ} \mathrm{C}$ overnight, followed by Cy3 anti-rabbit (Sigma) secondary antibodies diluted 1:800 for $2 \mathrm{~h}$ in PBS containing 1\% bovine serum albumin and $1 \%$ normal goat serum. The tissue was stained with DAPI (4',6-Diamidine-2' -phenylindole dihydrochloride) (1:1000) (Applichem) for $10 \mathrm{~min}$ before being embedded into Aqua-Poly/Mount. Fluorescent measurements were done with the Axio Imager Z1 (Zeiss, Göttingen, Germany) with 20 and 63-fold magnification.

\subsection{Statistics}

Sphingolipid levels and mRNA are presented as mean \pm SEM (standard error of the mean). Statistical analyses were performed with GraphPad Prism7 software or R. Significant differences between groups were assessed using one-way ANOVA for three or more groups or two-tailed, two-sided Student's t-tests for two groups. In case of significant ANOVAs, groups were mutually compared with t-tests by employing a correction of alpha according to Tukey.

\section{Results}

\subsection{Patient Data}

We collected 183 blood samples and 59 colon biopsies from 97 ulcerative colitis (UC) patients during a routine check-up at the department of gastroenterology at the Goethe University Frankfurt. Additionally, we collected 148 blood samples from 25 controls (healthy volunteers) within one year. According to the Mayo score, UC patients are divided into three groups (remission, mild, 
moderate/severe) (Table 2). Severity of disease and medication was taken from the electronic health report. All patients were aware of and consented to the study protocol.

Disease duration and medication of ulcerative colitis (UC) patients is shown in Figure 1A,B. The majority of patients in this study suffered from colitis for more than five years. Most abundantly prescribed medication are aminosalicylates (like 5-ASA), anti-TNF $\alpha$ antibodies and glucocorticoids, either as single treatment but also often used in combinations.

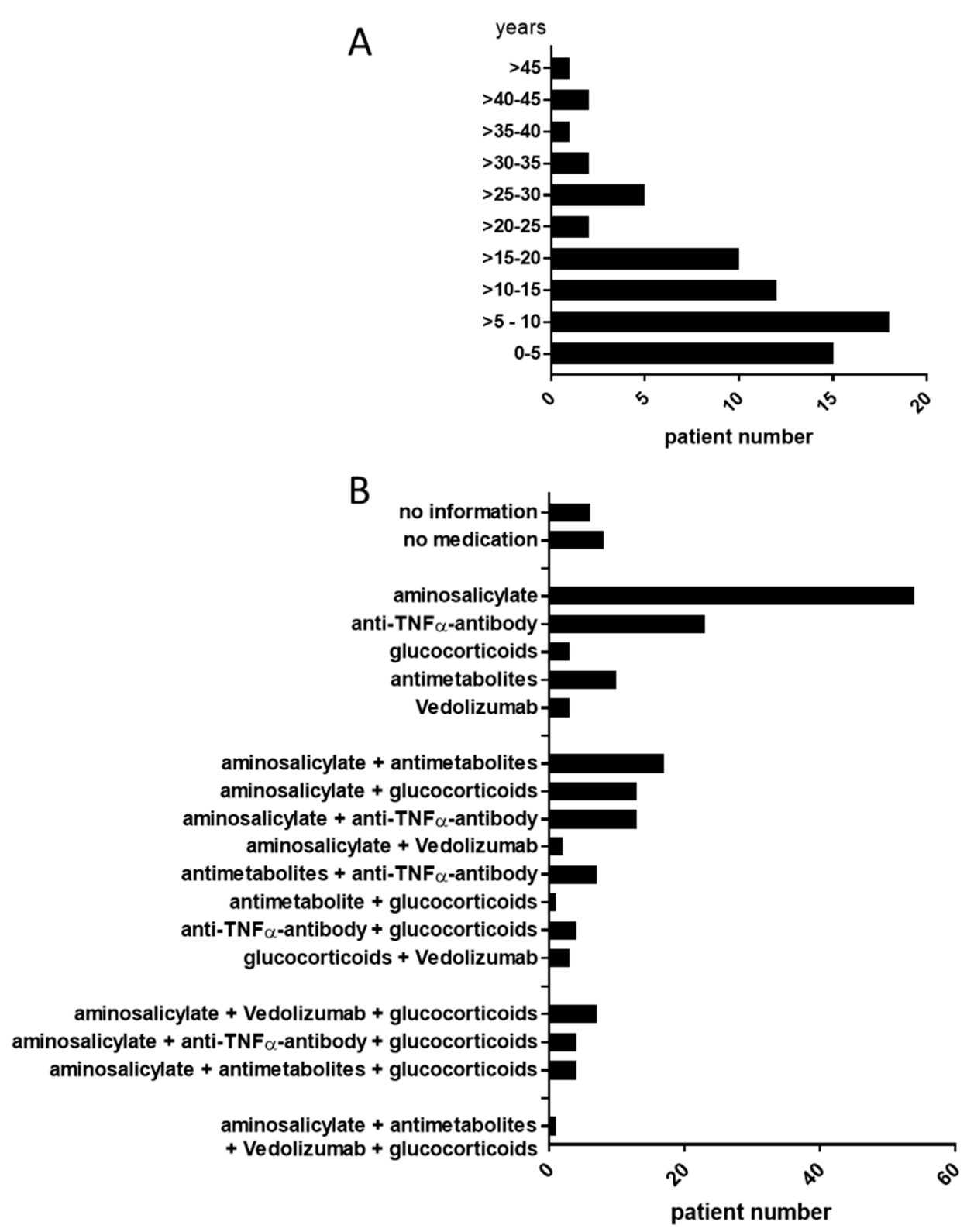

Figure 1. Patient data. (A) Time of disease duration in our ulcerative colitis (UC) patient cohort. (B) Overview of medical treatments of UC patients included in this study.

\subsection{Sphingolipids in Colon Tissue}

We examined the sphingolipid status in colon tissue from UC patients using biopsies that were taken during a routine colonoscopy. From each patient, biopsies were taken from inflamed tissue and from tissue that showed no inflammatory symptoms (control). One of the most conspicuous results was that in inflamed tissue, the levels of sphinganine (dhSph) and most dihydroceramides (dhCer) decreased significantly (Figure 2A,B), indicating that in inflamed tissue, the sphingolipid de novo synthesis is reduced. No significant differences could be observed in the levels of sphingosine (Sph), ceramide 
(Cer) or glucosylceramide (GlcCer) between inflamed or control tissue (Figure 2A,C-E). Instead, the concentrations of C16:0- and C24:0-lactosyl-ceramide (LacCer) increased in inflamed tissue in comparison to control tissue (Figure 2F). Sphingosine-1-phosphate (S1P) and sphinganine-1-phosphate (SA1P) concentrations could not be quantified due to their low amount and the limited tissue mass.

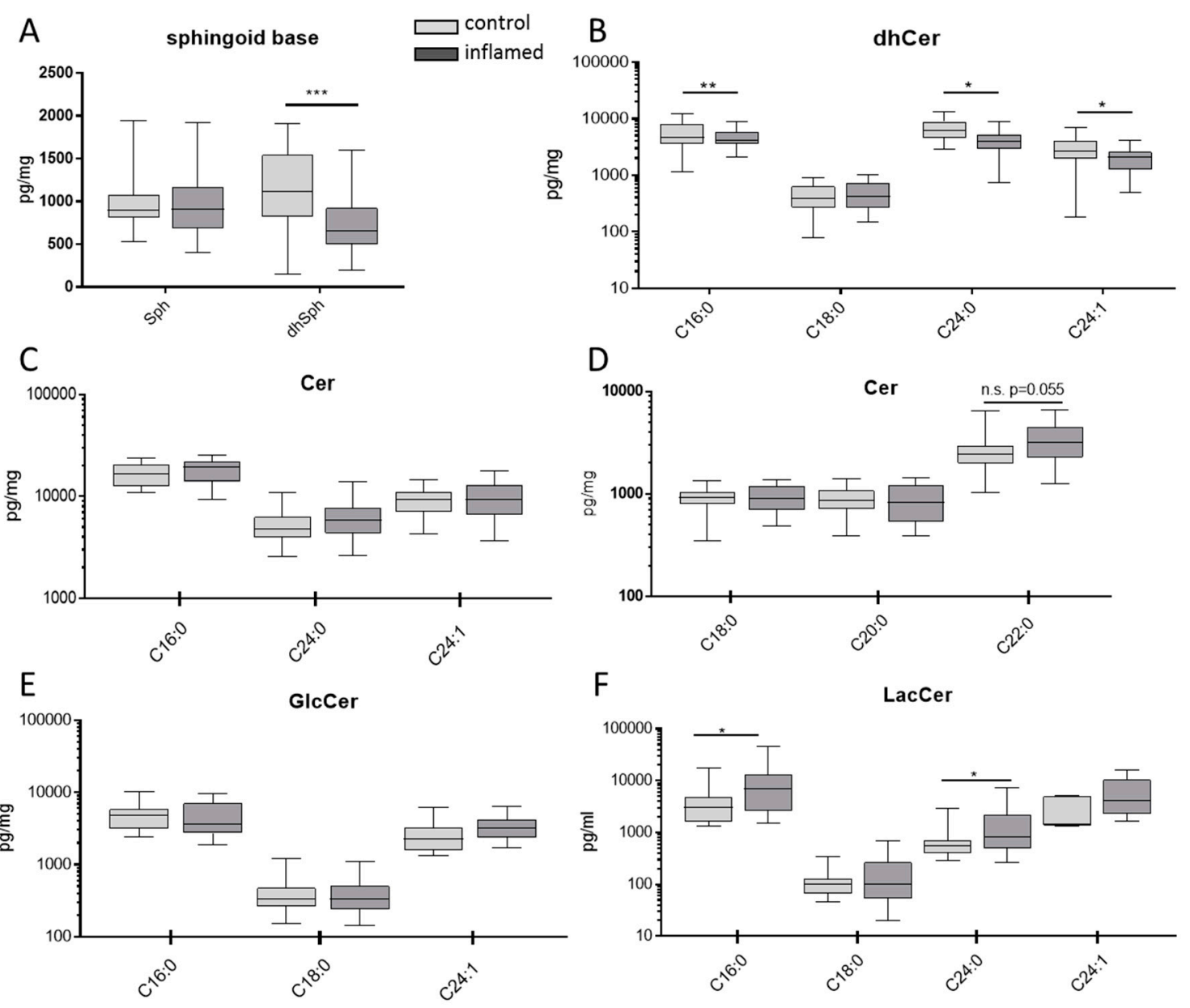

Figure 2. Sphingolipids in colon tissue. Colon samples from inflamed and control tissue were collected from UC patients undergoing diagnostic colonoscopy and sphingolipid concentrations where analyzed by LC-MS/MS. $n=27$. Statistical differences were analyzed by a paired T-test, $\alpha=0.05,\left({ }^{*} p<0.05\right.$, $\left.{ }^{* *} p<0.01,{ }^{* * *} p<0.001\right)$.

Because most of the dihydroceramides decreased, we investigated the expression level of important enzymes of the sphingolipid de novo synthesis. The expression of serine palmitoyltransferase (SPT) and the six ceramide synthases (CerS) were investigated on mRNA levels in control and inflamed colon tissue. SPT is a heterodimer, which consists of two subunits Sptlc1 and Sptlc2 or Sptlc1 and Sptlc3. For mRNA expression, we determined the expression level of Sptlc2 and Sptlc3. Interestingly, there were no significant changes in the expression level of Sptlc2 or 3 nor of the six CerS but CerS1 and CerS3 show a tendency to increase in inflamed tissue compared to control tissue (Figure 3A). CerS3 showed a 12-20-fold increase in mRNA expression in inflamed tissue of several patients in comparison to matched control tissue. Therefore, we detected CerS3 protein by immunohistochemical (IHC) staining of colon tissue. IHC staining of CerS3 in control and inflamed colon tissue showed an enhanced expression of CerS3 in inflamed tissue, whereby most CerS3 staining could be observed in the lamina propria region (Figure 3B), which let us suppose that the increase in CerS3 expression is a result of invaded immune cells, but further studies have to proof this assumption. 
A

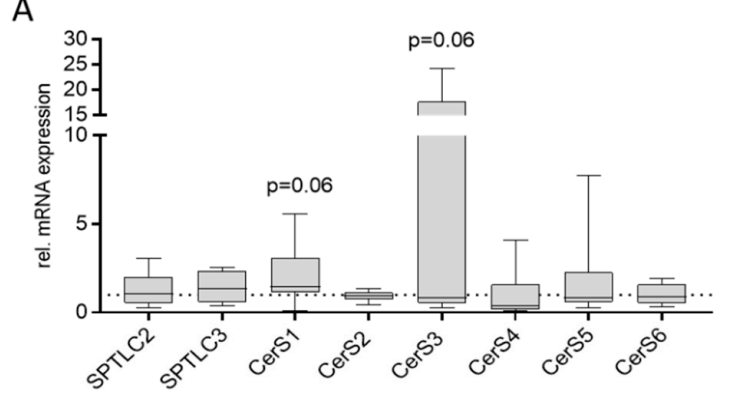

B

CerS3

Dapi

merge (64x)

merge (20x)
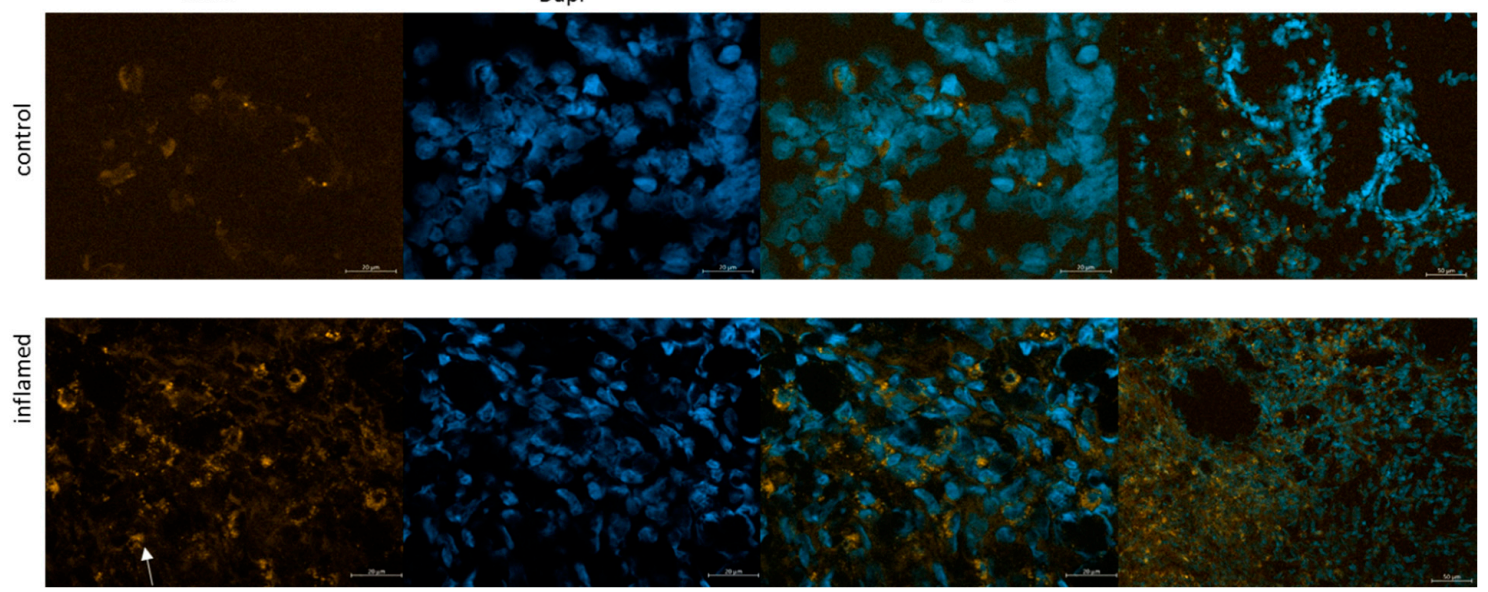

Figure 3. qRT-PCR and immunohistochemical staining of CerS and SPT in colon tissue. (A) mRNA levels of Sptlc2, Sptlc3 (SPT), CerS1-6 in inflamed and control tissue were detected by quantitative RT-PCR. CT levels were normalized to GAPDH and subsequently, related to the level of control (set to 1), using $2^{\wedge}(-\Delta \Delta \mathrm{CT})$ method. Data are means \pm SEM; $n=10-15$. Statistical differences were analyzed by GraphPad Prism using unpaired T-test, $p \leq 0.05$. (B) Immunohistochemistry of CerS3 in human colon tissue. CerS3 was stained with an anti-CerS3 antibody and a secondary antibody coupled to Cy3 and tissue was co-stained with DAPI. Original magnification: 63x and 20x; white arrow indicates cytoplasmic CerS3 staining in cell localized in the lamina propria.

\subsection{Lipids in Blood}

\subsubsection{Sphingolipids in Blood}

To investigate whether blood sphingolipid and other lipid levels in UC patients are disease -dependent regulated, we determined the sphingolipid concentrations in plasma from UC patients and controls (healthy volunteers) via LC-MS/MS and relative concentration of other lipids by LC-QTOFMS. The sphingolipid concentrations are shown to be dependent of the disease stage of the UC patients (Figure 4). The level of Sph, dhSph, Cer, GlcCer and most LacCer increased in blood of UC patients in comparison to control with a tendency to be most pronounced in patients who suffer from a moderate/severe disease stage. The concentration of C24:1-LacCer significantly decreased in the severe stage. Furthermore, the phosphorylated bases S1P and SA1P decreased in all stages of UC patients in comparison to control (Figure 4). The level of dhCer did not change between the different stages (data not shown). Disease stage-dependent changes in sphingolipid concentrations are also evident in single patients who underwent different stages over time (Figure S1). Pearson correlation analysis revealed that there are several highly significant correlations between the different sphingolipids in all patients which are shown in Figure S2. For example, there is a medium-to-strong linear positive interrelation between different long-chain ceramides, between distinct Cer and dhCer, Cer and GlcCer, different GlcCer, and C18:0-GlcCer and-LacCer (Figure S2). These data indicate that the different 
sphingolipids in blood are in a defined ratio to each other and that they significantly change in UC patients, which renders them interesting as possible biomarkers for disease control.

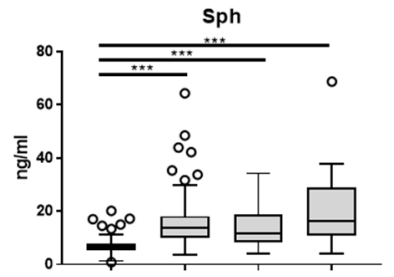

C16:0-Cer
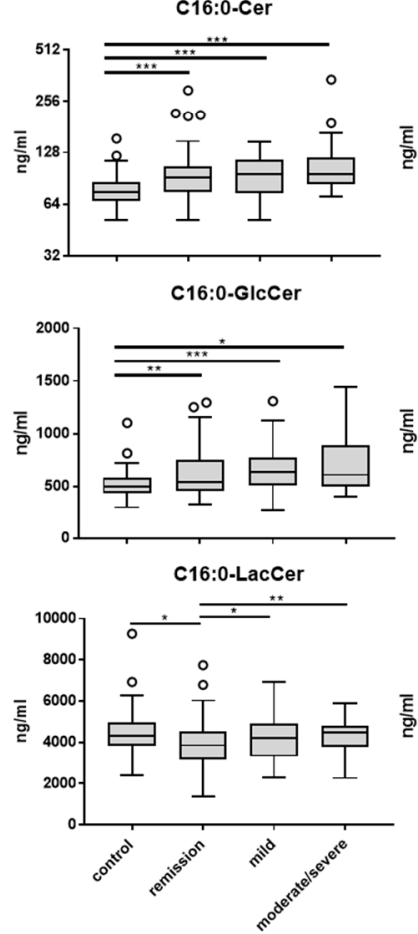
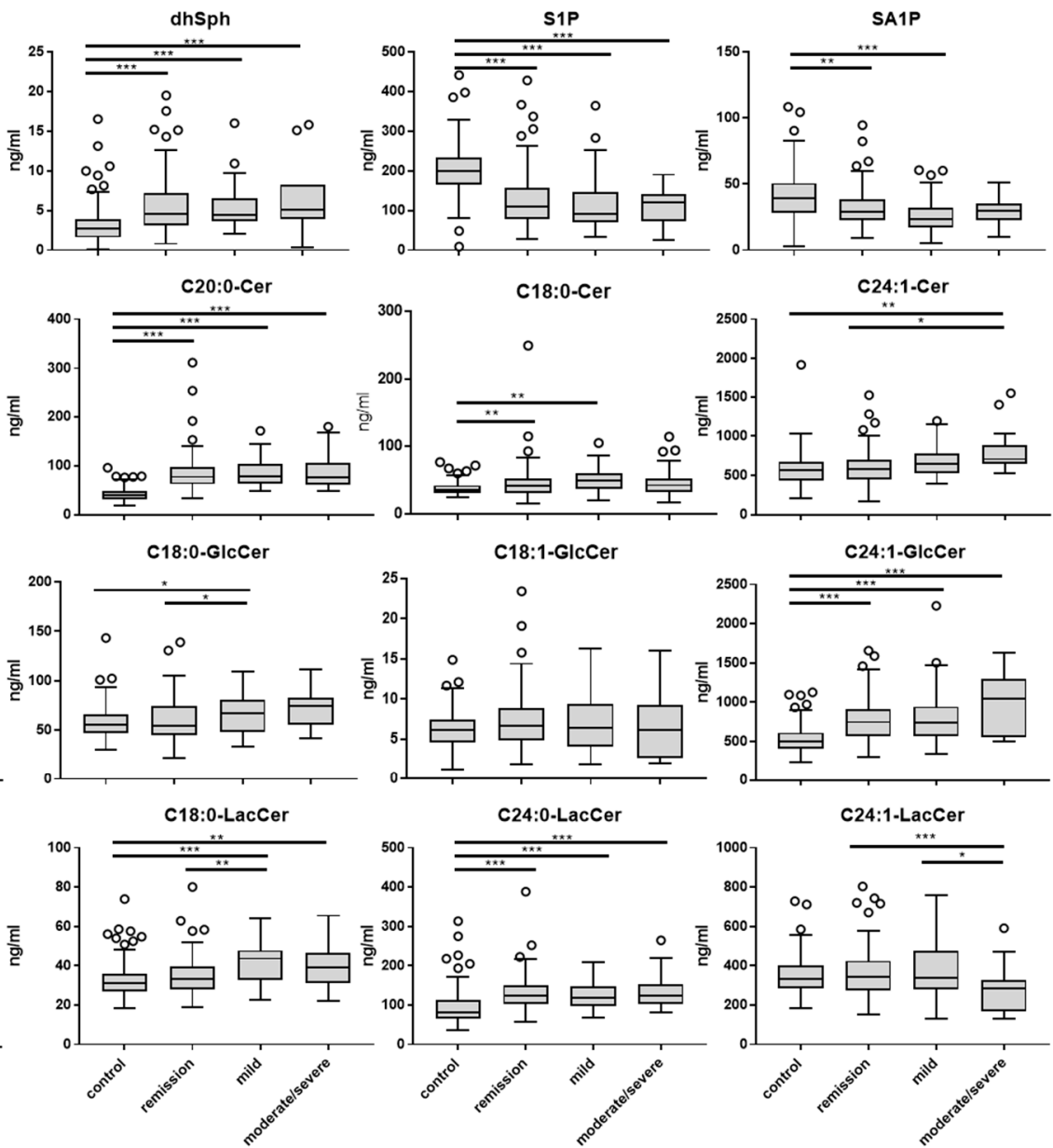

Figure 4. Sphingolipids in human plasma. Sphingolipids in human plasma was determined by LC-MS $/$ MS. $n_{\text {control }}=148 ; n_{\text {remission }}=102, n_{\text {moderate }}=43 ; n_{\text {acute }}=24$, Statistical analysis was performed with R, significant differences between groups were assessed using two-tailed ANOVA with Tukey multiple comparison, $\alpha=0.05$. ( $\left.{ }^{*} p<0.05,{ }^{* *} p<0.01,{ }^{* * *} p<0.001\right)$.

\subsubsection{Blood Sphingolipids in Correlation to Treatment with Aminosalicylate or Anti-TNFa}

To investigate if the sphingolipid status is influenced by the drugs used for the treatment of patients in our cohort, we looked for the sphingolipid levels in patients treated either with monotherapy aminosalicylate or anti-TNF- $\alpha$ antibody in comparison to patients who received no medication. The disease scores of the patients treated either with aminosalicylate only or anti-TNF- $\alpha$ antibody are comparable (aminosalicylate: $64 \%$ remission, $26 \%$ mild, $10 \%$ moderate/severe; anti-TNF- $\alpha$ antibody: $65 \%$ remission, $20 \%$ mild, $15 \%$ moderate/severe; no treatment (none): $100 \%$ remission). Only C18:0-Cer significantly increased in patients treated with monotherapy aminosalicylate in comparison to UC patients who were treated with anti-TNF- $\alpha$ antibody or received no medication. All other sphingolipids did not differ between the various groups (Figure 5). 

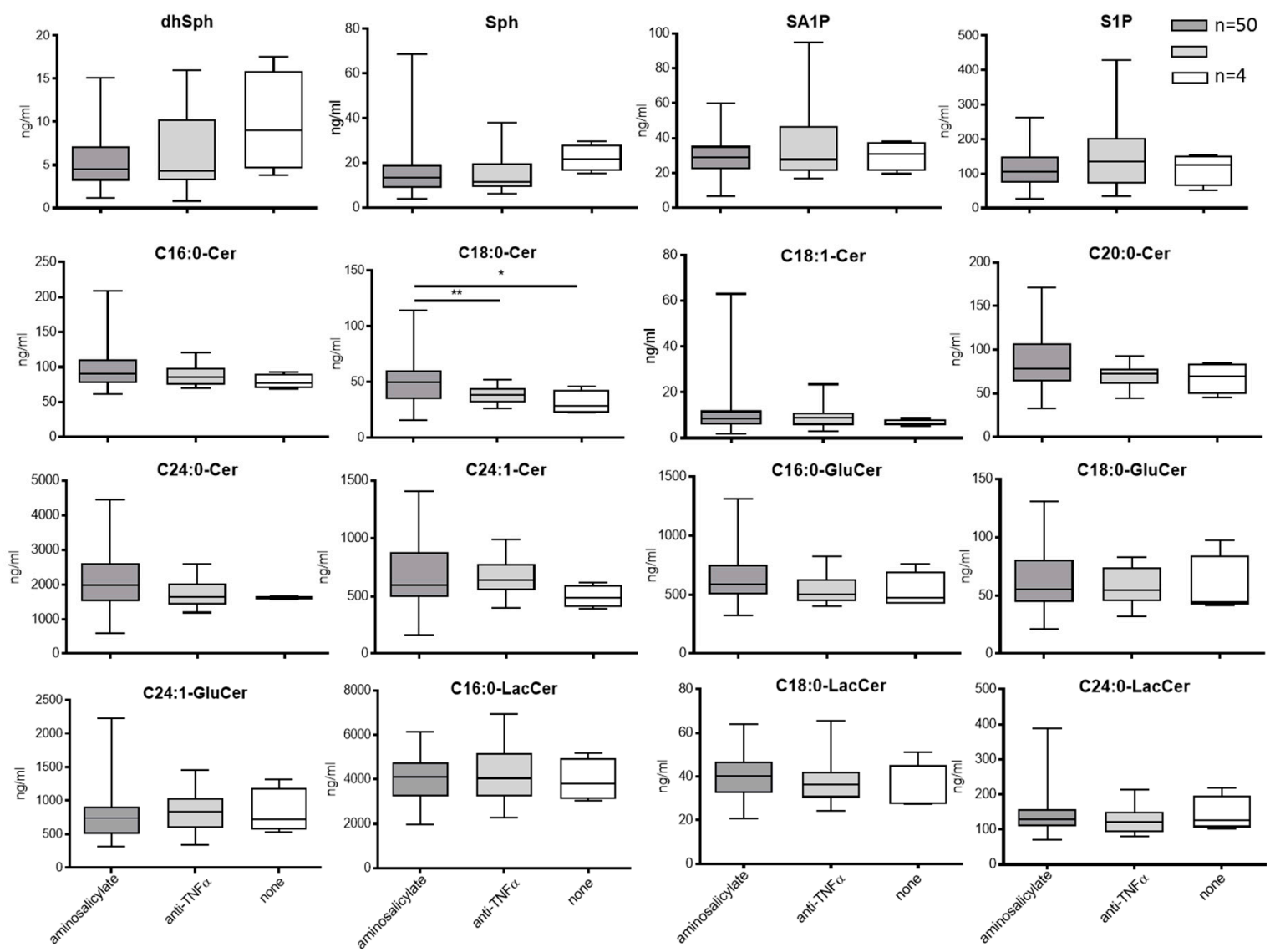

Figure 5. Sphingolipids in human plasma in relation to medical treatment. $n_{\text {none }}=6 ; n_{\text {anti TNF- } \alpha}=21$; $n_{\text {aminosalicylate }}=50$. Statistical analysis was done with $\mathrm{R}$, significant differences between groups were assessed using two-tailed ANOVA with Tukey multiple comparison, $\alpha=0.05$. $\left({ }^{*} p<0.05,{ }^{* *} p<0.01\right.$, $* * * p<0.001)$.

\subsubsection{Expression Level of Enzymes of the Sphingolipid De Novo Pathway}

We checked CerS expression in white blood cells (WBC) from UC patients in comparison to WBC of the healthy control group. CerS1 and CerS3 mRNA expression significantly increased in WBC from UC patients in comparison to WBC from controls (Figure 6), whereas CerS4 mRNA expression significantly decreased. The expression level of CerS2, CerS5 and CerS6 do not differ significantly in WBC from UC patients in comparison to controls (Figure 6). These data correlate with the enhanced expression level of CerS1 and CerS3 in inflamed colon tissue (Figure 2) facilitating our hypothesis that the invasion of immune cells is possibly responsible for these changes. However, CerS expression in WBC did not correlate with the sphingolipid level in plasma. Further analyses are needed to specify the cells that are mainly responsible for the sphingolipid content in plasma and to identify the immune cells that mainly express CerS1 and/or CerS3 in colon tissue.

\subsubsection{LC-QTOFMS Analysis of Lipids in Plasma}

Untargeted analysis of blood lipids indicates that several other lipids such as lysophosphatidylcholines (LPC), triglycerides (TG) and free fatty acids (FA) significantly differ between UC patients in remission and with mild disease (Figure 7A). Interestingly, the precursor of resolvins (eicosapentaenoic acid (EPA) and docosahexaenoic acid (DHA)) significantly increased in blood of UC patients with disease stage (Figure 7B). Therefore, other blood lipid concentrations might be determined as possible biomarkers for disease control. 


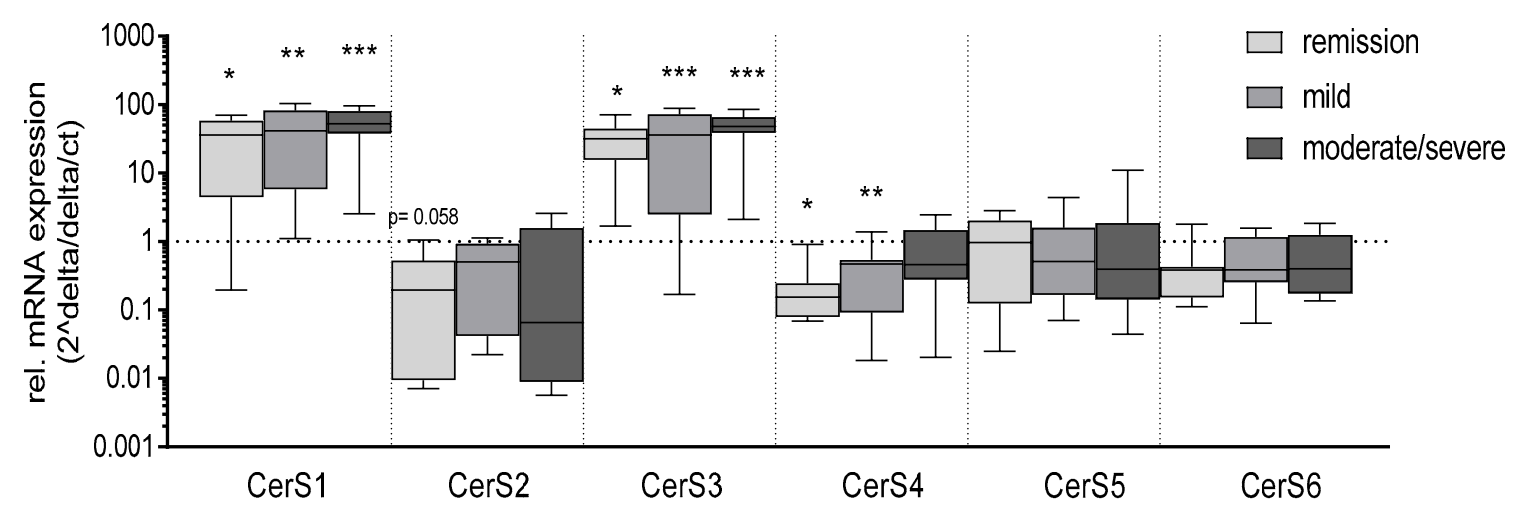

Figure 6. qRT-PCR of CerS in white blood cells from colitis patients and controls. mRNA levels of CerS1-6 in white blood cells (WBCs) were detected by quantitative RT-PCR. CT levels were normalized to GAPDH and subsequently related to the level of the control cohort (set to 1), using $2^{\wedge}(-\Delta \Delta \mathrm{CT})$ method. Data are means \pm SEM; $n=9-15$. Statistical differences were analyzed by one-way ANOVA with $\alpha$ Bonferroni post-hoc test. $\alpha=0.05$. $\left({ }^{*} p<0.05,{ }^{* *} p<0.01\right.$, $\left.{ }^{* *} p<0.001\right)$.

A

mild vs. remission

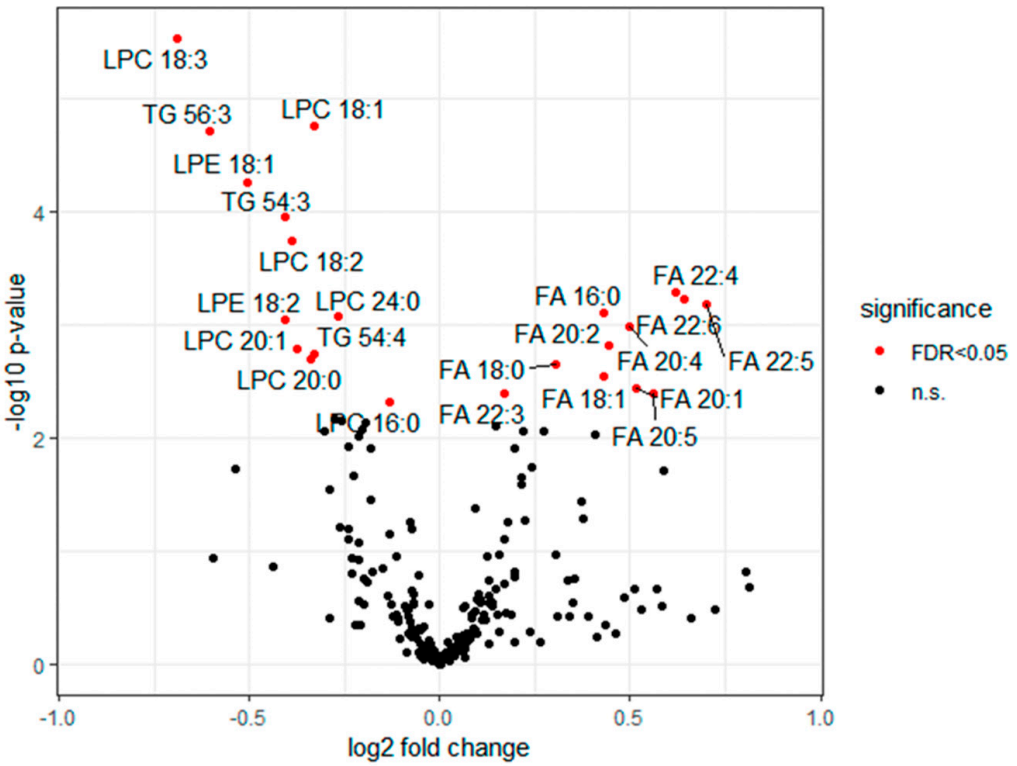

B
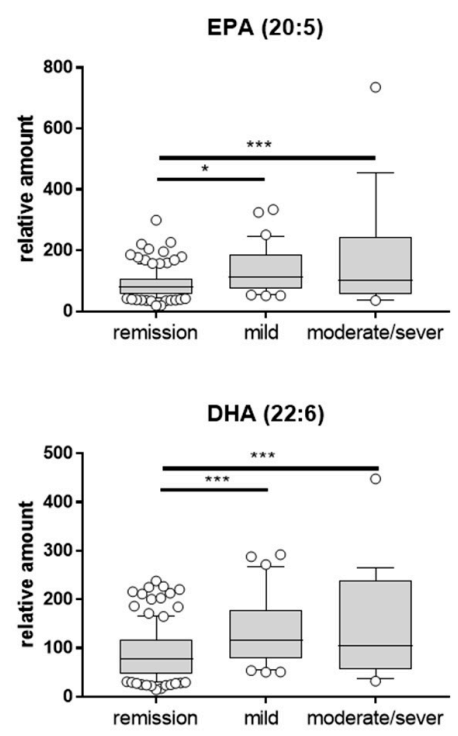

Figure 7. Lipids in human plasma. (A) Volcano blot of lipids in human plasma determined by LC-QTOFMS. Shown are the significances versus fold-changes of all lipids measured in plasma of UC patients who are in remission or suffer from mild disease. $n_{\text {remission }}=109, n_{\text {moderate }}=33$. Statistical analysis was performed with $\mathrm{R}$, significant differences between groups were assessed using two-tailed ANOVA with Tukey multiple comparison, $\alpha=0.05$. (B) Relative amounts of EPA and DHA in plasma of UC patients with different disease stages. $n_{\text {remission }}=109, n_{\text {moderate }}=33 ; n_{\text {acute }}=19$. Statistical analysis was performed with GraphPad, significant differences between groups were assessed using two-tailed ANOVA with Tukey multiple comparison, $\alpha=0.05$. (* $p<0.05$, ${ }^{* *} p<0.01$, ${ }^{* * *} p<0.001$ ).

\section{Discussion}

Ten years ago, Duan and Nilsson highlighted the importance of sphingolipids in the gut for inflammatory bowel disease [36]. The high turnover rate of mucosal cells is associated with a high rate of lipid synthesis to ensure membrane integrity of the epithelium. Since it has been shown that dietary sphingomyelin (SM) does not contribute to the SM pool in atherogenic cholesterol and triglyceride-rich plasma lipoproteins and there is no evidence that the mucosa can uptake plasma 
lipoprotein sphingolipids from the blood, the sphingolipids for renewal of the colon epithelium must be primarily produced locally by the de novo synthesis [36].

These observations were confirmed by a recently published study showing that the serine palmitoyltrasferase (SPT), which is the rate-limiting enzyme in the sphingolipid de novo synthesis, is essential for intestine cell survival and barrier function [31]. Tamoxifen induced knock down of Sptlc2 in colon epithelial cells lead to diarrhea and rectal bleeding, ending in death after 7-10 days. Repression of SPT suppressed the level of ceramides and sphingomyelins in membranes of colon cells, which was accompanied by a reduction of E-cadherin and mucin 2 and an induction of apoptosis in the colon. Disruption of the intestinal barrier function came along with an enhanced inflammation and bacterial invasion comparable to IBD in humans [31]. These data emphasize the importance of the sphingolipid de novo synthesis in the colon. Our data demonstrate that the sphingolipid de novo synthesis is repressed-especially in inflamed colon tissue from UC patients. This effect is not due to a reduced expression of Sptlc2/3 or CerS1-6. The human SPT is a heterodimer complex consisting of the subunits Sptlc1 and Sptlc2 or Sptlc3 and the composition might change dynamically in dependence of the tissue-specific expression of Sptlc2 and Sptlc3 [37,38]. However, because we saw no changes in the expression of Sptlc2 or Sptlc3 in our colon samples, we assume that inhibition of de novo synthesis might be related to the posttranscriptional regulation mechanism of SPT or CerS1- 6 activity [23,39].

In inflamed colon tissue, we could detect a low, insignificant increase in CerS1 and CerS3 expression but this is likely related to the invasion of immune cells. This hypothesis was supported by an enhanced expression of CerS1 and CerS3 mRNA in WBC of UC patients in comparison to controls. Additionally, we could show that especially LacCer-but not GlcCer-significantly increased in inflamed colons in colitis patients. LacCer serve as pattern-recognition receptors (PRRs) on human cells to which several pathogenic microorganisms, including Escherichia coli, Bordetella pertussis, Bacillus dysenteriae, Propionibacterium freudenreichii, and C. albicans, bind and thereby activate an innate immune response [40,41]. Therefore, an increase in LacCer in inflamed colon tissue contributes to an enhanced binding of pathogens, thereby increasing immune response and inflammation.

However, many different mouse models have been used to investigate the influence of distinct sphingolipids in colitis. In CerS2-knockout (ko) mice, depletion of very-long chain ceramides is connected with disruption of the membrane integrity by downregulation of tight junction protein occludin and zonula occludens-1 (ZO-1), leading to enhanced severity of AOM/DSS-induced colitis in these mice [28]. CerS6-ko mice are protected from T-cell-mediated colitis but show severe symptoms in the DSS-evoked colitis model [29]. Inhibition of acid sphingomyelinase, which hydrolases sphingomyelin to ceramide, leads to an amelioration of DSS-induced colitis, possibly by inhibition of the immune cell response in this mouse model [30]. However, in our cohort we could only detect a significant decrease in the dihydroceramide level but no significant changes in the ceramide level in inflamed colon in comparison to control tissue. Therefore, our data indicate that in human colon tissue, inhibition of de novo synthesis, but not a disequilibrium between different ceramides, contributes to the development of colitis.

Several papers investigated the role of S1P in colitis. Inhibition of sphingosine kinase 1 (SK1), either by inhibitors or using SK1-ko mice, ameliorates DSS-induced colitis in mice [35,42], whereas downregulation of SK2 enhanced DSS-induced colitis in mice, which has been ascribed to a concomitant upregulation of SK1 in these mice [43]. In contrast, the degradation of S1P in colon epithelial cells by sphingosine-1-phosphate phosphatase 2 promotes disruption of mucosal integrity and enhances DSS-induced colitis [33]. Therefore, the effect of S1P seems to depend on local or systemic production. We determined S1P in blood and colon tissue of UC patients. However, due to the low amounts of S1P in colon tissue and the small tissue sample size, S1P was under the detection limit. In human blood, we detected a reduced S1P level in UC patients in comparison to controls. Our data show no changes in S1P level between UC patients in different stages; in addition, the common drugs used for the treatment of UC patients had no influence on the S1P level (Figure 5). Also in pediatric IBD patients, no significant changes in S1P serum level between the different disease stages could be detected [25]. 
The serum S1P level decreased within other inflammatory conditions such as pancreatitis [44], or septic shock patients $[45,46]$. However, the opposite has also been reported, as the plasma S1P level increased in community-acquired pneumonia [47] or in human papillomavirus (HBV)-genotype D positive patients [48]. These data indicate that the plasma S1P level can be up- or down-regulated under various inflammatory conditions and that further studies investigating where plasma S1P comes from are needed. Erythrocytes are one of the main S1P sources, but also binding of S1P to high-density lipoprotein or serum albumin might be an important mechanism that contributes to alterations in the serum S1P level [49]. However, even we and others could not detect a disease-dependent change in the plasma S1P level; manipulation of the S1P signaling pathway by treating UC patients with ozanimod seems to be a promising approach that several clinical trials are ongoing, investigating S1P modulators in IBD [50].

In contrast to S1P, we detected a significant increase of several sphingolipids in plasma from UC patients in comparison to control plasma. Interestingly, also in plasma from MS patients, C16:0-Cer, C24:1-Cer, C16:0-GlcCer and C24:1-GlcCer were up-regulated in comparison with healthy controls [51], which further strengthen their usability as biomarkers for disease control under inflammatory conditions [52]. Until now, it is not known where sphingolipids in plasma mainly come from. For S1P, it is known that it is produced and secreted from hematopoietic cells such as erythrocytes and endothelial cells [53]. Ceramides and other lipophilic sphingolipids are released as extracellular vesicles from different cells such as platelets, immune cells and from different tissues $[54,55]$. Further studies are needed to determine which cells are mainly responsible for the sphingolipid content in plasma in different diseases and to estimate their usefulness as biomarkers for disease control.

In addition to sphingolipids, we also detected other lipids in the blood of UC patients and revealed significant changes in free fatty acids (Figure 7). Saturated fatty acids can activate toll-like receptors, thereby enhancing inflammation, whereas unsaturated fatty acids counteract this mechanism [56,57]. DHA and EPA are the precursors of resolvins that are attributed to anti-inflammatory effects. Resolvins, such as RvE1-3 (derived from EPA) or RVD1-4, and maresins (derived from DHA) are synthesized endogenously and are important players in the resolution of colitis-associated inflammation [58-61]. Resolvins themselves are hard to detect in human blood samples but animal studies have shown that in a DSS-induced colitis mice model, the supplementation of fish oil enriched with omega- 3 fatty acids such as EPA and DHA relieved the symptoms of colitis-associated inflammation by influencing redox-regulation and inhibition of pro-inflammatory processes [62,63]. In humans, it has been shown that supplementation with fish oil resulted in improvements in the histology index in UC patients [64]. The nutrition supplementation with EPA also has protective effects in patients with UC and is, therefore, suggested to be used as adjuvant to maintain symptom-free remission [65]. However, for patients taking these fatty acids as a dietary supplement, they may not be further useful as biomarkers for disease control.

\section{Conclusions}

Our study and literature data suggest that inhibition of the sphingolipid de novo synthesis in colon tissue might be a mechanism contributing to the development of UC (see also Figure A1). Furthermore, several sphingolipids and free fatty acids in the blood may be useful biomarkers for disease control, as they increase with severity. However, further studies are needed to investigate how useful these lipids are in detecting early changes in disease stages either in the direction of resolution or disease progression. Highly sensitive and selective detection methods have already been published [66] and are a prerequisite for further studies.

Supplementary Materials: The following are available online at http://www.mdpi.com/2077-0383/8/7/971/s1, Table S1. The Mayo Score, Figure S1. Plasma sphingolipid changes of single patients in dependency of disease stage, Figure S2. Correlation analysis of plasma sphingolipid level.

Author Contributions: S.B., S.O., K.E-H., S.B., K.B. acquisition of data (sample preparation, RT-PCR, IHC), statistical analysis, final approval; J.H., I.B., A.K., K.S. acquisition of patients and patient samples/data; L.H., S.T., 
D.T., G.G. LC-MS/MS analysis and statistical analysis, final approval, E.H. statistical analysis, S.S. acquisition of control samples and final approval, S.G. conception, design of the study, interpretation of data drafting and final approval.

Funding: This work was funded by the Deutsche Forschungsgemeinschaft (DFG) [grant number: SFB 1039/2, Z01, B05]; the LOEWE Lipid Signaling Forschungszentrum Frankfurt (LiFF); the Landesoffensive zur Entwicklung wissenschaftlich-ökonomischer Exzellenz (LOEWE), and the center "Translationale Medizin und Pharmakologie" (TMP).

Conflicts of Interest: The authors declare no conflict of interest. The authors have no financial interests or connections, direct or indirect, or other situations that might raise the question of bias in the work reported or the conclusions, implications, or opinions stated. The funders had no role in the design of the study; in the collection, analyses, or interpretation of data; in the writing of the manuscript, or in the decision to publish the results.

\section{Appendix A}

healthy colon epithelial layer

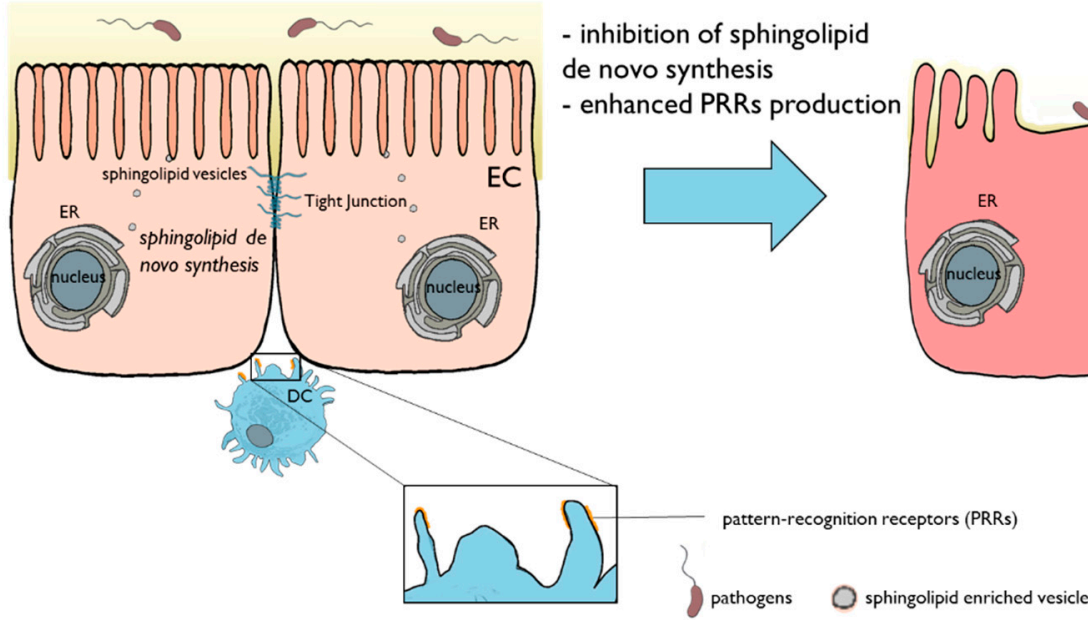

epithelium from ulcerative colitis patients

Figure A1. In healthy colon tissue, tight junctions stabilize the epithelial layer. The functionality of the tight junctions is dependent on proper membrane lipid composition, which is warranted by, e.g., vesicular delivery of sphingolipids that are built de novo in the endoplasmic reticulum (ER). In colon tissue from ulcerative colitis patients, de novo sphingolipid synthesis is reduced, leading to the disruption of membrane integrity. Furthermore, LacCers, which can function as pattern-recognition receptors, are upregulated, leading to an enhanced binding of pathogens and thereby, activation of immune cells.

\section{References}

1. Da Silva, B.C.; Lyra, A.C.; Rocha, R.; Santana, G.O. Epidemiology, demographic characteristics and prognostic predictors of ulcerative colitis. World J. Gastroenterol. 2014, 20, 9458-9467. [CrossRef] [PubMed]

2. Ng, S.C.; Shi, H.Y.; Hamidi, N.; Underwood, F.E.; Tang, W.; Benchimol, E.I.; Panaccione, R.; Ghosh, S.; $\mathrm{Wu}$, J.C.Y.; Chan, F.K.L.; et al. Worldwide incidence and prevalence of inflammatory bowel disease in the 21st century: A systematic review of population-based studies. Lancet 2018, 390, 2769-2778. [CrossRef]

3. Molodecky, N.A.; Soon, I.S.; Rabi, D.M.; Ghali, W.A.; Ferris, M.; Chernoff, G.; Benchimol, E.I.; Panaccione, R.; Ghosh, S.; Barkema, H.W.; et al. Increasing incidence and prevalence of the inflammatory bowel diseases with time, based on systematic review. Gastroenterology 2012, 142, 46-54.e42. [CrossRef] [PubMed]

4. Peyrin-Biroulet, L.; Sandborn, W.; Sands, B.E.; Reinisch, W.; Bemelman, W.; Bryant, R.V.; D'Haens, G.; Dotan, I.; Dubinsky, M.; Feagan, B.; et al. Selecting Therapeutic Targets in Inflammatory Bowel Disease (STRIDE): Determining Therapeutic Goals for Treat-to-Target. Am. J. Gastroenterol. 2015, 110, 1324-1338. [CrossRef] [PubMed] 
5. Bressler, B.; Marshall, J.K.; Bernstein, C.N.; Bitton, A.; Jones, J.; Leontiadis, G.I.; Panaccione, R.; Steinhart, A.H.; Tse, F.; Feagan, B.; et al. Clinical practice guidelines for the medical management of nonhospitalized ulcerative colitis: The Toronto consensus. Gastroenterology 2015, 148, 1035-1058.e1033. [CrossRef] [PubMed]

6. Harbord, M.; Eliakim, R.; Bettenworth, D.; Katsanos, K.; Karmiris, K.; Kopylov, U.; Kucharzik, T.; Molnár, T.; Raine, T.; Sebastian, S.; et al. Third European Evidence-based Consensus on Diagnosis and Management of Ulcerative Colitis. Part 2: Current Management. J. Crohns Colitis 2017, 11, 769-784. [CrossRef] [PubMed]

7. Kucharzik, T.; Dignass, A.U.; Atreya, R.; Bokemeyer, B.; Esters, P.; Herrlinger, K.; Kannengießer, K.; Kienle, P.; Langhorst, J.; Schreiber, S.; et al. [Updated S3-Guideline Colitis ulcerosa. German Society for Digestive and Metabolic Diseases (DGVS)_AWMF Registry 021/009]. Z. Gastroenterol. 2018, 56, 1087-1169.

8. Degagne, E.; Saba, J.D. S1 pping fire: Sphingosine-1-phosphate signaling as an emerging target in inflammatory bowel disease and colitis-associated cancer. Clin. Exp. Gastroenterol. 2014, 7, 205-214.

9. Kappos, L.; Radue, E.W.; O'Connor, P.; Polman, C.; Hohlfeld, R.; Calabresi, P.; Selmaj, K.; Agoropoulou, C.; Leyk, M.; Zhang-Auberson, L.; et al. A placebo-controlled trial of oral fingolimod in relapsing multiple sclerosis. N. Engl. J. Med. 2010, 362, 387-401. [CrossRef]

10. Izzo, R.; Figliuzzi, M.M.; Monteleone, G. Sphingosine-1-phosphate receptor: A novel therapeutic target in ulcerative colitis. Expert Rev. Clin. Immunol. 2016, 12, 1137-1139. [CrossRef]

11. Maceyka, M.; Harikumar, K.B.; Milstien, S.; Spiegel, S. Sphingosine-1-phosphate signaling and its role in disease. Trends Cell Biol. 2012, 22, 50-60. [CrossRef] [PubMed]

12. Abdel Hadi, L.; Di Vito, C.; Riboni, L. Fostering Inflammatory Bowel Disease: Sphingolipid Strategies to Join Forces. Mediators Inflamm. 2016, 2016, 3827684. [CrossRef] [PubMed]

13. Sandborn, W.J.; Feagan, B.G.; Wolf, D.C.; Dhaens, G.; Vermeire Md, P.S.; Hanauer, S.B.; Ghosh, S.; Smith, H.; Cravets, M.; Frohna, P.; et al. Ozanimod Induction and Maintenance Treatment for Ulcerative Colitis. N. Engl. J. Med. 2016, 374, 1754-1762. [CrossRef] [PubMed]

14. Rivera, J.; Proia, R.L.; Olivera, A. The alliance of sphingosine-1-phosphate and its receptors in immunity. Nat. Rev. Immunol. 2008, 8, 753-763. [CrossRef] [PubMed]

15. Castro, B.M.; Prieto, M.; Silva, L.C. Ceramide: A simple sphingolipid with unique biophysical properties. Prog. Lipid Res. 2014, 54, 53-67. [CrossRef] [PubMed]

16. He, X.; Huang, Y.; Li, B.; Gong, C.H.; Schuchman, E.H. Deregulation of sphingolipid metabolism in Alzheimer's disease. Neurobiol. Aging 2010, 31, 398-408. [CrossRef] [PubMed]

17. Maceyka, M.; Spiegel, S. Sphingolipid metabolites in inflammatory disease. Nature 2014, 510, 58-67. [CrossRef] [PubMed]

18. Coant, N.; Sakamoto, W.; Mao, C.; Hannun, Y.A. Ceramidases, roles in sphingolipid metabolism and in health and disease. Adv. Biol. Regul. 2017, 63, 122-131. [CrossRef] [PubMed]

19. Albi, E.; Alessenko, A.; Grosch, S. Sphingolipids in Inflammation. Mediators Inflamm. 2018, $2018,7464702$. [CrossRef] [PubMed]

20. Hartmann, D.; Wegner, M.S.; Wanger, R.A.; Ferreirós, N.; Schreiber, Y.; Lucks, J.; Schiffmann, S.; Geisslinger, G.; Grösch, S. The equilibrium between long and very long chain ceramides is important for the fate of the cell and can be influenced by co-expression of CerS. Int. J. Biochem. Cell Biol. 2013, 45, 1195-1203. [CrossRef] [PubMed]

21. Ben-David, O.; Futerman, A.H. The role of the ceramide acyl chain length in neurodegeneration: Involvement of ceramide synthases. Neuromol. Med. 2010, 12, 341-350. [CrossRef] [PubMed]

22. Eckl, K.M.; Tidhar, R.; Thiele, H.; Oji, V.; Hausser, I.; Brodesser, S.; Preil, M.L.; Onal-Akan, A.; Stock, F.; Müller, D.; et al. Impaired epidermal ceramide synthesis causes autosomal recessive congenital ichthyosis and reveals the importance of ceramide acyl chain length. J. Investig. Dermatol. 2013, 133, 2202-2211. [CrossRef] [PubMed]

23. Wegner, M.S.; Schiffmann, S.; Parnham, M.J.; Geisslinger, G.; Grösch, S. The enigma of ceramide synthase regulation in mammalian cells. Prog. Lipid Res. 2016, 63, 93-119. [CrossRef] [PubMed]

24. Franzosa, E.A.; Sirota-Madi, A.; Avila-Pacheco, J.; Fornelos, N.; Haiser, H.J.; Reinker, S.; Vatanen, T.; Hall, A.B.; Mallick, H.; McIver, L.J.; et al. Gut microbiome structure and metabolic activity in inflammatory bowel disease. Nat. Microbiol. 2019, 4, 293-305. [CrossRef] [PubMed] 
25. Suh, J.H.; Degagne, E.; Gleghorn, E.E.; Setty, M.; Rodriguez, A.; Park, K.T.; Verstraete, S.G.; Heyman, M.B.; Irek, M.; Gildengorin, G.L.; et al. Sphingosine-1-Phosphate Signaling and Metabolism Gene Signature in Pediatric Inflammatory Bowel Disease: A Matched-case Control Pilot Study. Inflamm. Bowel Dis. 2018, 24, 1321-1334. [CrossRef] [PubMed]

26. Diab, J.; Hansen, T.; Goll, R.; Stenlund, H.; Ahnlund, M.; Jensen, E.; Moritz, T.; Florholmen, J.; Forsdahl, G. Lipidomics in Ulcerative Colitis Reveal Alteration in Mucosal Lipid Composition Associated With the Disease State. Inflamm. Bowel Dis. 2019. [CrossRef] [PubMed]

27. Kim, Y.R.; Volpert, G.; Shin, K.O.; Kim, S.Y.; Shin, S.H.; Lee, Y.; Sung, S.H.; Lee, Y.-M.; Ahn, J.-H.; Park, W.J.; et al. Ablation of ceramide synthase 2 exacerbates dextran sodium sulphate-induced colitis in mice due to increased intestinal permeability. J. Cell Mol. Med. 2017, 21, 3565-3578. [CrossRef] [PubMed]

28. Oertel, S.; Scholich, K.; Weigert, A.; Thomas, D.; Schmetzer, J.; Trautmann, S.; Wegner, M.-S.; Heinfried, H.; Radeke, H.H.; Filmann, N.; et al. Ceramide synthase 2 deficiency aggravates AOM-DSS-induced colitis in mice: Role of colon barrier integrity. Cell Mol. Life Sci. 2017, 74, 3039-3055. [CrossRef] [PubMed]

29. Helke, K.; Angel, P.; Lu, P.; Garrett-Mayer, E.; Ogretmen, B.; Drake, R.; Voelkel-Johnson, C. Ceramide Synthase 6 Deficiency Enhances Inflammation in the DSS model of Colitis. Sci. Rep. 2018, 8, 1627. [CrossRef]

30. Xiong, Y.; Zhu, X.D.; Wan, P.; Ren, Y.P.; Wang, C.; Yan, R.W.; Guo, Y.; Bai, A.P. Inhibition of ASM activity ameliorates DSS-induced colitis in mice. Prostaglandins Other Lipid Mediat. 2019, 140, 26-30. [CrossRef]

31. Li, Z.; Kabir, I.; Tietelman, G.; Huan, C.; Fan, J.; Worgall, T.; Jiang, X.C. Sphingolipid de novo biosynthesis is essential for intestine cell survival and barrier function. Cell Death Dis. 2018, 9, 173. [CrossRef] [PubMed]

32. Suzuki, S.; Tanaka, A.; Nakamura, H.; Murayama, T. Knockout of Ceramide Kinase Aggravates Pathological and Lethal Responses in Mice with Experimental Colitis. Biol. Pharm. Bull. 2018, 41, 797-805. [CrossRef] [PubMed]

33. Huang, W.C.; Liang, J.; Nagahashi, M.; Avni, D.; Yamada, A.; Maceyka, M.; Wolen, A.R.; Kordula, T.; Milstien, S.; Oravecz, T. Sphingosine-1-phosphate phosphatase 2 promotes disruption of mucosal integrity, and contributes to ulcerative colitis in mice and humans. FASEB J. 2016, 30, 2945-2958. [CrossRef] [PubMed]

34. Snider, A.J.; Wu, B.X.; Jenkins, R.W.; Sticca, J.A.; Kawamori, T.; Hannun, Y.A.; Obeid, L.M. Loss of neutral ceramidase increases inflammation in a mouse model of inflammatory bowel disease. Prostaglandins Other Lipid Mediat. 2012, 99, 124-130. [CrossRef] [PubMed]

35. Snider, A.J.; Kawamori, T.; Bradshaw, S.G.; Orr, K.A.; Gilkeson, G.S.; Hannun, Y.A.; Obeid, L.M. A role for sphingosine kinase 1 in dextran sulfate sodium-induced colitis. FASEB J. 2009, 23, 143-152. [CrossRef] [PubMed]

36. Duan, R.D.; Nilsson, A. Metabolism of sphingolipids in the gut and its relation to inflammation and cancer development. Prog. Lipid Res. 2009, 8, 62-72. [CrossRef]

37. Hornemann, T.; Wei, Y.; von Eckardstein, A. Is the mammalian serine palmitoyltransferase a high-molecular-mass complex? Biochem. J. 2007, 405, 157-164. [CrossRef]

38. Hornemann, T.; Richard, S.; Rütti, M.F.; Wei, Y.; von Eckardstein, A. Cloning and initial characterization of a new subunit for mammalian serine-palmitoyltransferase. J. Biol. Chem. 2006, 281, 37275-37281. [CrossRef]

39. Tamehiro, N.; Mujawar, Z.; Zhou, S.; Zhuang, D.Z.; Hornemann, T.; von Eckardstein, A.; Fitzgerald, M.L. Cell polarity factor Par3 binds SPTLC1 and modulates monocyte serine palmitoyltransferase activity and chemotaxis. J. Biol. Chem. 2009, 284, 4881-24890. [CrossRef]

40. Nakayama, H.; Ogawa, H.; Takamori, K.; Iwabuchi, K. GSL-enriched membrane microdomains in innate immune responses. Arch. Immunol. Ther. Exp. (Warsz) 2013, 61, 217-228. [CrossRef]

41. Sato, T.; Iwabuchi, K.; Nagaoka, I.; Adachi, Y.; Ohno, N.; Tamura, H.; Seyama, K.; Fukuchi, Y.; Nakayama, H.; Takamori, K. Induction of human neutrophil chemotaxis by Candida albicans-derived beta-1,6-long glycoside side-chain-branched beta-glucan. J. Leukoc. Biol. 2006, 80, 204-211. [CrossRef] [PubMed]

42. Maines, L.W.; Fitzpatrick, L.R.; French, K.J.; Zhuang, Y.; Xia, Z.; Keller, S.N.; Upson, J.J.; Smith, C.D. Suppression of ulcerative colitis in mice by orally available inhibitors of sphingosine kinase. Dig. Dis. Sci. 2008, 53, 997-1012. [CrossRef] [PubMed]

43. Liang, J.; Nagahashi, M.; Kim, E.Y.; Harikumar, K.B.; Yamada, A.; Huang, W.C.; Hait, N.C.; Allegood, J.C.; Price, M.M.; Takabe, K. Sphingosine-1-phosphate links persistent STAT3 activation, chronic intestinal inflammation, and development of colitis-associated cancer. Cancer Cell 2013, 23, 107-120. [CrossRef] [PubMed] 
44. Xiao, J.; Lin, H.; Liu, B.; Xia, Z.; Zhang, J.; Jin, J. Decreased S1P and SPHK2 are involved in pancreatic acinar cell injury. Biomark. Med. 2019. [CrossRef] [PubMed]

45. Winkler, M.S.; Märtz, K.B.; Nierhaus, A.; Daum, G.; Schwedhelm, E.; Kluge, S.; Gräler, M.H. Loss of sphingosine 1-phosphate (S1P) in septic shock is predominantly caused by decreased levels of high-density lipoproteins (HDL). J. Intensive Care 2019, 7, 23. [CrossRef] [PubMed]

46. Wu, X.; Hou, J.; Li, H.; Xie, G.; Zhang, X.; Zheng, J.; Wang, J.; Gao, F.; Yao, Y.; Fang, X.; et al. Inverse Correlation Between Plasma Sphingosine-1-Phosphate and Ceramide Concentrations in Septic Patients and Their Utility in Predicting Mortality. Shock 2019, 51, 718-724. [CrossRef] [PubMed]

47. Hsu, S.C.; Chang, J.H.; Hsu, Y.P.; Bai, K.J.; Huang, S.K.; Hsu, C.W. Circulating sphingosine-1-phosphate as a prognostic biomarker for community-acquired pneumonia. PLoS ONE 2019, 14, e0216963. [CrossRef]

48. Mücke, V.T.; Jakobi, K.; Knop, V.; Thomas, D.; Mücke, M.M.; Peiffer, K.H.; Zeuzem, S.; Sarrazin, C.; Pfeilschifter, J.; Grammatikos, G. Serum sphingolipid levels associate with upcoming virologic events and HBV genotype D in a cohort of patients with HBeAg-negative HBV infection. PLoS ONE 2018, 13, e0207293. [CrossRef]

49. Egom, E.E.; Shiwani, H.A.; Pharithi, R.B.; Canning, R.; Khan, B.; Hiani, Y.E.; Maher, V. Dynamic changes of the composition of plasma HDL particles in patients with cardiac disease: Spotlight on sphingosine-1-phosphate/serum amyloid A ratio. Clin. Exp. Pharmacol. Physiol. 2018, 45, 319-325. [CrossRef]

50. Danese, S.; Furfaro, F.; Vetrano, S. Targeting S1P in Inflammatory Bowel Disease: New Avenues for Modulating Intestinal Leukocyte Migration. J. Crohns Colitis 2018, 12, S678-S686. [CrossRef]

51. Kurz, J.; Brunkhorst, R.; Foerch, C.; Blum, L.; Henke, M.; Gabriel, L.; Ulshöfer, T.; Ferreirós, N.; Parnham, M.J.; Schiffmann, S.; et al. The relevance of ceramides and their synthesizing enzymes for multiple sclerosis. Clin. Sci. (Lond.) 2018, 132, 1963-1976. [CrossRef] [PubMed]

52. Kurz, J.; Parnham, M.J.; Geisslinger, G.; Schiffmann, S. Ceramides as Novel Disease Biomarkers. Trends Mol. Med. 2019, 25, 20-32. [CrossRef] [PubMed]

53. Hla, T.; Venkataraman, K.; Michaud, J. The vascular S1P gradient-cellular sources and biological significance. Biochim. Biophys. Acta 2008, 1781, 477-482. [CrossRef] [PubMed]

54. Pienimaeki-Roemer, A.; Ruebsaamen, K.; Boettcher, A.; Orsó, E.; Scherer, M.; Liebisch, G.; Kilalic, D.; Ahrens, N.; Schmitz, G. Stored platelets alter glycerophospholipid and sphingolipid species, which are differentially transferred to newly released extracellular vesicles. Transfusion 2013, 53, 612-626. [CrossRef] [PubMed]

55. Verderio, C.; Gabrielli, M.; Giussani, P. Role of sphingolipids in the biogenesis and biological activity of extracellular vesicles. J. Lipid Res. 2018, 59, 1325-1340. [CrossRef] [PubMed]

56. Hwang, D.H.; Kim, J.A.; Lee, J.Y. Mechanisms for the activation of Toll-like receptor $2 / 4$ by saturated fatty acids and inhibition by docosahexaenoic acid. Eur. J. Pharmacol. 2016, 785, 24-35. [CrossRef] [PubMed]

57. Lee, J.Y.; Sohn, K.H.; Rhee, S.H.; Hwang, D. Saturated fatty acids, but not unsaturated fatty acids, induce the expression of cyclooxygenase-2 mediated through Toll-like receptor 4. J. Biol. Chem. 2001, 276, 16683-16689. [CrossRef]

58. Das, U.N. Inflammatory bowel disease as a disorder of an imbalance between pro- and anti-inflammatory molecules and deficiency of resolution bioactive lipids. Lipids Health Dis. 2016, 15, 11. [CrossRef]

59. Weylandt, K.H.; Kang, J.X.; Wiedenmann, B.; Baumgart, D.C. Lipoxins and resolvins in inflammatory bowel disease. Inflamm. Bowel Dis. 2007, 13, 797-799. [CrossRef]

60. Schwanke, R.C.; Marcon, R.; Bento, A.F.; Calixto, J.B. EPA- and DHA-derived resolvins' actions in inflammatory bowel disease. Eur. J. Pharmacol. 2016, 785, 156-164. [CrossRef]

61. Jin, J.; Lu, Z.; Li, Y.; Cowart, L.A.; Lopes-Virella, M.F.; Huang, Y. Docosahexaenoic acid antagonizes the boosting effect of palmitic acid on LPS inflammatory signaling by inhibiting gene transcription and ceramide synthesis. PLoS ONE 2018, 13, e0193343. [CrossRef] [PubMed]

62. Sharma, M.; Kaur, R.; Kaushik, K.; Kaushal, N. Redox modulatory protective effects of omega-3 fatty acids rich fish oil against experimental colitis. Toxicol. Mech. Methods 2019, 29, 244-254. [CrossRef] [PubMed]

63. Cho, J.Y.; Chi, S.G.; Chun, H.S. Oral administration of docosahexaenoic acid attenuates colitis induced by dextran sulfate sodium in mice. Mol. Nutr. Food Res. 2011, 55, 239-246. [CrossRef] [PubMed]

64. Stenson, W.F.; Cort, D.; Rodgers, J.; Burakoff, R.; DeSchryver-Kecskemeti, K.; Gramlich, T.L.; Beeken, W. Dietary supplementation with fish oil in ulcerative colitis. Ann. Intern. Med. 1992, 116, 609-614. [CrossRef] [PubMed] 
65. Scaioli, E.; Sartini, A.; Bellanova, M.; Campieri, M.; Festi, D.; Bazzoli, F.; Belluzzi, A. Eicosapentaenoic Acid Reduces Fecal Levels of Calprotectin and Prevents Relapse in Patients With Ulcerative Colitis. Clin. Gastroenterol. Hepatol. 2018, 16, 1268-1275.e1262. [CrossRef]

66. Toewe, A.; Balas, L.; Durand, T.; Geisslinger, G.; Ferreirós, N. Simultaneous determination of PUFA-derived pro-resolving metabolites and pathway markers using chiral chromatography and tandem mass spectrometry. Anal. Chim. Acta 2018, 1031, 185-194. [CrossRef] [PubMed]

(C) 2019 by the authors. Licensee MDPI, Basel, Switzerland. This article is an open access article distributed under the terms and conditions of the Creative Commons Attribution (CC BY) license (http://creativecommons.org/licenses/by/4.0/). 